\title{
Using ratio-weighted sums to project data into future scenarios: the case study of heating systems
}

Author 1 (corresponding author)

- Miquel Banchs-Piqué

- School of Civil Engineering and Surveying, University of Portsmouth, Portland Building, Portland Street, Portsmouth PO1 3AH, UK

- miquel.banchs-pique@port.ac.uk, +44 2392842428

- ORCID: 0000-0002-9022-2453

Miquel Banchs-Piqué is PhD Student in the School of Civil Engineering \& Surveying at the University of Portsmouth and is member of the Doctoral Training Alliance Energy Group. He is also an associate member of the Energy Institute (UK) and of the German Physical Society (DPG). He started and coordinated the Portsmouth local chapter of the Economy for the Common Good and collaborates with other social, environmental and scientific projects. Before moving to Portsmouth, he spent six years in Göttingen (Germany), where he did research for his MSc thesis and worked in the Laboratory for Cavitation and Micro-Erosion. He studied physics and photonics in Barcelona.

Author 2

- Dr. David J Hutchinson

- Faculty of Technology, University of Portsmouth, Portsmouth, UK

- ORCID: 0000-0002-0023-4689

Dr David Hutchinson is currently Innovation Manager for the Faculty of Technology, University of Portsmouth. In addition, he holds responsibility, as PI, for a portfolio of projects with a total value of over $\mathrm{f} 6$ million. These all concentrate on supporting zero carbon innovation and alternative energy solutions, particularly in collaboration between University and Business.

Dr Hutchinson is a member of the UKRI NERC advisory network, and is vice-chair of Future South, a business-led triple helix partnership that is working towards a zero carbon economy in the South of England. The partnership has created over 250 clean growth jobs, helped to establish a community bank, worked with over 150 businesses on low carbon innovation projects, and created Greentech South the first 'Energy and Environment' accredited cluster in the UK, and a member of the International Cleantech Network. 
Author 3

- Prof. Victor M Becerra

- School of Engineering, University of Portsmouth, Portsmouth, UK

- ORCID: 0000-0002-3790-4236

Professor Victor Becerra is currently a Professor of Power Systems Engineering at the School of Energy and Electronic Engineering, University of Portsmouth, UK, where he has been since 2015. Between 1989 and 1991, he was employed as an Electrical Engineer at C.V.G. Edelca, Caracas, Venezuela. Between 1994 and 1999 he was a post-doctoral Research Fellow at the Control Engineering Research Centre at City University of London. During the period between 2000 and 2015 he was an academic at the School of Systems Engineering, University of Reading, UK, where he became a Professor of Automatic Control in 2012. His current research interests consider a range of issues related to power systems, as well as the methods and applications of automatic control. Professor Becerra is a Fellow of the IET and a Senior Member of the IEEE.

\title{
Author 4
}

- Prof. Mark R Gaterell

- School of Civil Engineering and Surveying, University of Portsmouth, Portsmouth, UK

- ORCID: 0000-0002-0504-4841

Mark Gaterell is Professor of Sustainable Construction in the Faculty of Technology at the University of Portsmouth. He has been involved with different aspects of the field of sustainable built environments for over twenty-five years, working for companies such as Thames Water, Scott Wilson and the Building Research Establishment as well as receiving research degrees from the University of Cambridge and Imperial College. Current research activities consider a broad range of issues relating to sustainable buildings, from the analysis of the relationship between buildings and open spaces at a redevelopment scale and the implications of different urban futures, to the consideration of elements of both new build and the existing building stock at an individual building scale. This work is characterised by multidisciplinary approaches, working together with ecologists, social scientists, urban designers, architects, economists and engineers.

\begin{abstract}
Carefully planning the future of the building sector is key to mitigate greenhouse gas (GHG) emissions. The largest contributor of the building sector to GHG emissions is the energy used for space and water heating. Therefore, information on its possible future evolutions can be very valuable. Future scenarios can be used to investigate the behaviour of existing data into the future. Here, electricity demand data are projected into four distinct futures of the household's use of electric heating systems. These projections offer, however, only partial information about the possible evolutions of the residential energy demand, as they account only for changes in the type of heating systems used. This information could, together with a range of other projections, be used to improve the planning of the future residential sector.
\end{abstract}

Keywords: Future scenarios, foresight, data projection, ratio-weighted sum, household energy demand, heating systems, Designing Resilient Cities. 
Abbreviations:

$\begin{array}{ll}\text { GHG } & \text { GreenHouse Gas } \\ \text { DRC } & \text { Designing Resilient Cities } \\ \text { NSP } & \text { New Sustainability Paradise } \\ \text { PR } & \text { Policy Reform } \\ \text { MF } & \text { Market Forces }\end{array}$

\section{Introduction}

There exists consensus in the scientific community on the fact that climate change is humanmade and driven by greenhouse gases (GHG) (Cook et al., 2016). The International Energy Agency estimates that the building sector needs to reduce its carbon dioxide emissions by $77 \%$ compared to the 2013 baseline in order to achieve the goal to limit the temperature rise to $2^{\circ} \mathrm{C}$ (IEA, 2013). The UK has recently committed to net zero carbon emissions by 2050 (HM UK Parliament, 2019) and it recognises that the built environment plays a crucial role in achieving this target (Department of Energy and Climate Change, 2009).

Space heating is the largest contributor to household energy demand by far. Together with water heating - the second largest slice - in 2011 they accounted for around $80 \%$ of the UK household energy demand (Palmer and Cooper, 2013). Therefore, the number of dwellings using electric heating has a huge impact in the electricity network's load. Besides, the energy source used for heating by the vast majority of homes in the UK (more than 80\%) is gas. Most of the non-gas energy used for heating, as well as virtually all the energy used for nonheating-related purposes in UK households, is electricity (Ofgem, 2015) —of which $42.7 \%$ of its 2019 generation was by means of fossil fuels, mostly gas (BEIS, 2019). Therefore, these two sources of energy account for almost all the energy used in UK households.

Therefore, carefully planning the future of the building sector, and especially that of the heating systems they use, is key to mitigate greenhouse gas emissions and to ensure the resilience of the energy network systems that provide them.

However, development does not follow a linear path, which renders it impossible to predict the future (Schwartz, 2012). If uncertainty is not taken into account in its design phase, a seemingly appropriate solution may stop delivering its advantages within its life-time if the future is different than anticipated. Scenario analysis can help avoid assets growing stranded and resources being lost by portraying a range of possible futures against which to test any design (Banchs-Piqué et al., 2020; Hunt et al., 2012; Lombardi et al., 2012). If a solution delivers its intended benefits in a wide range of sufficiently distinct future scenarios which extend to the extremes of plausibility, one can be confident that the solution is resilient (Lombardi et al., 2012).

One tool which is especially suited to study the future performance of interventions in the urban environment and, therefore, in the building sector, is 'Designing Resilient Cities' (DRC) (Lombardi et al., 2012). DRC use the 'Urban Futures Method' (Rogers et al., 2012) on integrated scenarios - considering major economic, social, cultural, institutional, technological and environmental questions at the same time - adapted to urban UK in 2050 (Boyko et al., 2012; Lombardi et al., 2012; Rogers et al., 2012). These scenarios are based on those developed by the Global Scenarios Group, which are explorative scenarios covering a broad range of distinct futures (Raskin, Electris and Rosen, 2010). They are logical and plausible evolutions from the world today and are internally consistent (Gallopin et al., 1997). 
The projection of micro-data into scenarios is not common although a method to do this is under development by the authors of this paper. The core of this method are ratio-weighted sums of the average energy demand of different groups of a household population. The groups are defined so that all the households in one group share the same (or similar) features according to a given variable; for example, for the variable income, households could be grouped by social class, or for the variable household size, households would be grouped according to the number of people forming the household. Knowing the household average energy demand and the household population ratio of each group, it is trivial to obtain the total average energy demand per household - summation of the products 'average energy demand per household' times 'ratio' of each household group. For a known data set, these values are, of course, known or easy to find. However, it is in principle unknown how these values could change in the future.

The key point of the projection method is that different variables are projected separately. This means that only the projected variable varies in each projection while the others are kept constant. Therefore, as the characteristics related to the given variable are constant within each group, there is nothing related to their energy demand that changes for the group. And so, the average energy demand of each group can be considered constant, which implies that only the relative ratio of the groups may change in a projection. Then, it follows that if the characteristics of a future scenario allow for the determination of the ratio of each group, one can obtain the average energy demand of any known data in that scenario. Note again that such projections take only into account the changes introduced by the evolution of the given variable. This method, thus, allows to obtain an approximation to the average energy demand in a scenario only by evaluating the ratio of each group in that scenario. To obtain a more complete picture, projections of other relevant variables can be calculated.

This method can be used with scenarios described by a set of indicators of which at least some are related to the data intended to be projected. The data must include enough relevant metadata related to these indicators (so that the data can be sorted in groups) and the scenarios cannot be too disruptive (they cannot introduce new groups or behaviours) to be able to obtain a projection. This paper provides a case study of the use of this method. The evolution of dwelling heating systems is chosen as a case study due to its relevant contribution to the building GHG emissions (Palmer and Cooper, 2013). As a result, information on its future evolutions can be very valuable and could be used to improve the planning of the future residential sector and the energy networks that supply it. The projections obtained with this method do not take into account any technological progress or any other future feature which is not conveyed by the scenarios. Additionally, the projection of dwelling heating systems is partial, as residential energy demand depends on many other variables (other than the heating system used by the dwellings) which may vary differently in the future scenarios.

\section{Data, scenarios and projections method}

The data used for this case study are the household data obtained for the CER Smart Metering Project - Electricity Customer Behaviour Trial (CER, 2012). This trial took place between July 142009 and Dec 31 2010, and contains the power consumption data (in 30-minute intervals) and the answers to a pre- and a post-trial survey for around 3500 households in Ireland. The surveys convey information on the demographics of the households, which includes information about the heating systems they use. The answers of the pre-trial survey have been used as metadata to form the groups of households. 
The scenarios where these data are projected are the ones developed by DRC (Lombardi et $a l ., 2012$ ) and adapted by Banchs-Piqué et al. (2020). Their names, which give a good idea of their characteristics, are New Sustainability Paradigm (NSP), Policy Reform (PR), Market Forces (MF), and Fortress World (FW). Find a brief description of these scenarios in Table 1 and a complete one in the book by Lombardi et al. (2012). The characteristics which the projections have to follow are these of the indicator Use of electric space (and water) heating from the extension of the DRC provided by Banchs-Piqué et al. (2020) and found in Table 2.

The households of the sample have been sorted according to whether they use electric heating (sub-index $e$ ) or not (sub-index $n$ ) and the expression used to find the projections is the following:

$$
E^{S c}=E_{\mathrm{e}} \cdot f_{\mathrm{e}}^{S c}+E_{n} \cdot f_{n}^{S c}
$$

Where $E$ are average electricity demand per household, $f$ ratio of the household group, and super-index $S c$ indicates scenario.

Table 1: Brief description of the scenarios from Designing Resilient Cities (DRC) (Lombardi et al., 2012).

\begin{tabular}{|c|c|c|c|}
\hline NSP & PR & MF & FW (rich $35: 65$ poor) \\
\hline $\begin{array}{l}\text { An ethos of 'one planet } \\
\text { living' facilitates a shared } \\
\text { vision for more sustainable } \\
\text { living and much improved } \\
\text { quality of life. New socio- } \\
\text { economic arrangements } \\
\text { result in changes to the } \\
\text { character of urban industrial } \\
\text { civilisation. Local is valued } \\
\text { but global links also play a } \\
\text { role. A sustainable and more } \\
\text { equitable future is emerging } \\
\text { from new values, a revised } \\
\text { model of development and } \\
\text { the active engagement of } \\
\text { civil society. } \\
\text { Key driver: Equity and } \\
\text { sustainability }\end{array}$ & $\begin{array}{l}\text { Policy Reform depends on } \\
\text { comprehensive and } \\
\text { coordinated government } \\
\text { action for poverty reduction } \\
\text { and environmental } \\
\text { sustainability, negating } \\
\text { trends toward high inequity. } \\
\text { The values of consumerism } \\
\text { and individualism persist, } \\
\text { creating a tension with } \\
\text { policies that prioritise } \\
\text { sustainability. } \\
\text { Key driver: Economic } \\
\text { growth with greater equity }\end{array}$ & $\begin{array}{l}\text { Market Forces relies on the } \\
\text { self-correcting logic of } \\
\text { competitive markets. } \\
\text { Current demographic, } \\
\text { economic, environmental, } \\
\text { and technological trends } \\
\text { unfold without major } \\
\text { surprise. Competitive, open } \\
\text { and integrated markets drive } \\
\text { world development. Social } \\
\text { and environmental concerns } \\
\text { are secondary. } \\
\text { Key driver: Competitive, } \\
\text { open global markets }\end{array}$ & $\begin{array}{l}\text { Powerful individuals, groups } \\
\text { and organisations develop an } \\
\text { authoritarian response to the } \\
\text { threads of resource scarcity } \\
\text { and social breakdown by } \\
\text { forming alliances to protect } \\
\text { their own interests. Security } \\
\text { and defensibility of } \\
\text { resources are paramount for } \\
\text { these privileged rich elites. } \\
\text { An impoverished majority } \\
\text { exists outside the fortress. } \\
\text { Policy and regulations exist } \\
\text { but enforcement may be } \\
\text { limited. Armed forces act to } \\
\text { impose order, protect the } \\
\text { environment and prevent } \\
\text { societal collapse. } \\
\text { Key driver: Protection and } \\
\text { control of resources. }\end{array}$ \\
\hline
\end{tabular}

Table 2: Characteristics of indicator Use of electric (and water) heating from Banchs-Piqué et al. (2020).

\begin{tabular}{|c|c|c|c|c|}
\hline \multirow{2}{*}{$\begin{array}{l}\text { Metric } \\
\text { Base (UK 2012) }\end{array}$} & NSP & \multirow[b]{3}{*}{$\begin{array}{c}\text { PR } \\
\text { 介 } \\
\text { There is an important } \\
\text { growth in the use of } \\
\text { electric heating, } \\
\text { mainly incentivised } \\
\text { by the government. } \\
\text { Probably the increase } \\
\text { is slightly smaller in } \\
\text { electric water heating } \\
\text { as technologies as } \\
\text { solar thermal are } \\
\text { normally not used for } \\
\text { space heating. }\end{array}$} & MF & FW \\
\hline & & & & \multirow[b]{2}{*}{$\begin{array}{c}\Uparrow \mid \Downarrow \\
\text { The general trend is } \\
\text { slight decrease in the } \\
\text { use of electric space } \\
\text { and water heating } \\
\text { systems. However, it } \\
\text { increases within the } \\
\text { rich. }\end{array}$} \\
\hline $\begin{array}{r}8.5 \%(2.2 \mathrm{~m} \\
\text { households }) \\
\text { gas: }>80 \% \\
\text { other: } \sim 10 \%\end{array}$ & $\begin{array}{c}\Uparrow \\
\text { There is a moderate } \\
\text { increase in use of } \\
\text { electric space heating. }\end{array}$ & & $\begin{array}{c}\Uparrow \\
\text { There is a slow } \\
\text { increase in the use of } \\
\text { electric space and } \\
\text { water heating systems. }\end{array}$ & \\
\hline
\end{tabular}


The heating systems used by the households in the data set are very mixed, including a large percentage of households using oil and solid heating systems besides electric and gas systems. This is not ideal since the scenarios assume only one heating system per household, and electric and gas heating systems to be the norm, with the rest being mainly district heating which is not represented in the data. As the data projected are electricity demand data, and in order to follow the assumptions of the scenarios, the groups used for the projection sort only the households exclusively using electric heating systems (61 households, $5.59 \%$ of the subsample), and the households not using electric heating at all (1031 households, $94.41 \%)$. The ratios of each group in the data and these obtained for the future scenarios are shown in Table 3.

Table 3: Household group ratios in the data set and the future scenarios.

\begin{tabular}{|l|c|c|c|c|c|}
\hline \multicolumn{1}{|c|}{ Group } & Data & NSP & PR & MF & FW (rich | poor) \\
\hline Electrical heating & 0.06 & 0.43 & 0.36 & 0.20 & $0.10(0.22 \mid 0.03)$ \\
\hline Other heating & 0.94 & 0.57 & 0.64 & 0.80 & $0.89(0.78 \mid 0.97)$ \\
\hline
\end{tabular}

\section{Projections}

The projections of daily and total household electricity demand averaged for the period December 2009 - November 2010 for the sub-sample of the data set are shown in Table 4. The daily electricity profiles for the same period, and for the summer and winter in the period, for both groups as in the sample, and the projections in the future scenarios are shown in Figure 1. This figure also shows a comparison between the projections for NSP and FW (the two most different scenarios) in winter and in summer.

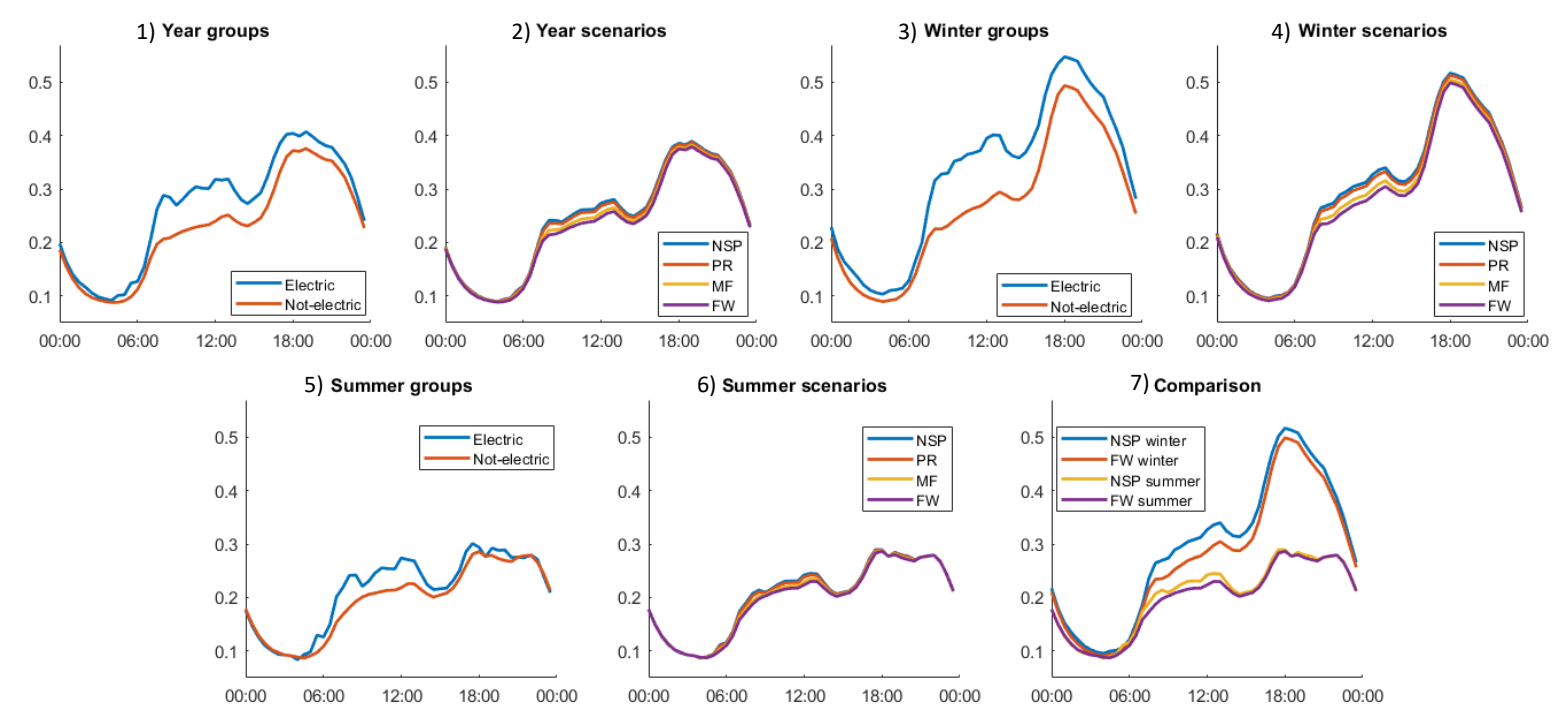

Figure 1: Average household electricity demand profile for different periods of time (year, winter and summer) for the household groups and the projections to the different scenarios, and comparison between NSP and FW for winter and summer. Demand in $k W h$.

Table 4: Daily and total household average electricity demand in a one-year period (December 2009 - November 2010) for the 'Electric heating' and 'Other' groups, the subsample of data, and the projections for all scenarios.

\begin{tabular}{|l|l|l|l|l|l|l|l|}
\hline$(\mathrm{kWh})$ & Electric & Other & Total data & NSP & PR & MF & FW \\
\hline Daily average & 12.69 & 10.91 & 11.08 & 11.67 & 11.55 & 11.26 & 11.08 \\
\hline Total average & 4632 & 3982 & 4018 & 4261 & 4216 & 4112 & 4044 \\
\hline
\end{tabular}




\section{Discussion}

As it can be seen in parts 1), 5) and especially 3) from Figure 1, and in Table 4, the difference in electricity demand between the group using exclusively electric heating systems and the group not using electric heating systems at all is very small. Space heating is the largest contributor to household energy demand by far (Palmer and Cooper, 2013). The difference in electricity demand between using or not using electric heating systems should be very large. Therefore, the difference in electricity demand between these groups was expected to be much larger. This small difference between the household groups translates to small differences between scenarios and it is most likely due to unreliable metadata (note the large difference between the summer and winter electricity demand of the group without electric heating systems, which suggests significant use of electricity for heating purposes). The metadata used to sort the groups was obtained via very long telephone surveys. It is likely that a number of respondents were unsure of the heating systems their household use or tired of providing answers — giving unreliable information. Something similar happens with other not-straightforward questions from the survey, i.e. number of bedrooms has been used as proxy for dwelling size in the paper by (McLoughlin, Duffy and Conlon, 2012) because the answers from the survey question about dwelling size are not reliable.

Even though the differences between scenarios are small, one can see interesting outcomes. First of all, one can see that despite the extensive differences in group ratios, the differences between scenarios are very small. The reason is the small difference in energy demand explained above. The differences in electricity demand are, as expected, larger in winter than in summer due to the distinct use of the heating systems between these sessions. And, in all the scenarios except for the poor in FW there is an increase in the use of electric heating systems, which is due to a higher use of heat pumps (the decrease within the poor is because most cannot afford anything else than burning biomass to heat their dwellings). Most remarkably, the increase in electricity demand correlates with the degree of sustainability of the scenario. This is because in NSP and PF energy use is heavily electrified with electricity produced by no GHG emitting means in order to cut carbon emissions.

Although the data do not contain households using district heating, which appears in the extended characteristics of the indicator Use of electric space (and water) heating (see the paper by Banchs-Piqué et al. (2020)), this does not make the scenarios be too disruptive. This is because the data projected is electricity demand and, therefore, the relevant groups for these projections are those sorting households which use electric heating systems, and those which do not - which include these using any type of in-house heating system as well as these using district heating. The scenario FW could be seen as too disruptive because the data do not contain households in extreme poverty or in informal developments. However, these effects are not taken into account with this specific projection. They would be taken into account with other projections such as these of variables related to the income or the type of buildings households live in. And, the latter (if they could be obtained) would portray effects of much higher order than the former; i.e., the effects of the rampant poverty are much more profound than the effects of the changes in heating systems use in FW. This should be taken in consideration when combining sets of projections to obtain a meaningful picture of a scenario. This fact shows a disadvantage of this projection method: when a scenario is heavily shaped by one specific (group of) variable(s), the projections of other variables portray effects of very secondary order in comparison. 


\section{Conclusions}

The projection method can effectively be used to project data into future scenarios. A single projection is, however, partial and should be combined with a range of projections representative of the properties of the scenarios. Yet, a single projection can convey interesting or counterintuitive information about the scenarios as seen with the increase of electricity demand the more sustainable a scenario is.

This method relies highly in the quality of the data and metadata. The very small difference in the electricity demand between the group of households using exclusively electric heating systems and the group not using them at all, suggests that the metadata of the projected data does not provide accurate information in this domain.

\section{Acknowledgments}

CER Smart Metering Project - Electricity Customer Behaviour Trial, 2009-2010 accessed via the Irish Social Science Data Archive - www.ucd.ie/issda.

\section{References}

Banchs-Piqué, M. et al. (2020) 'Adapting futures scenarios to study UK household energy demand', Engineering Sustainability, 173(5), pp. 241-256. doi: 10.1680/jensu.18.00057.

Boyko, C. et al. (2012) 'Benchmarking sustainability in cities: The role of indicators and future scenarios', Global Environmental Change. Elsevier Ltd, 22(1), pp. 245-254. doi: 10.1016/j.gloenvcha.2011.10.004.

Commission for Energy Regulation (CER) (2012) 'CER Smart Metering Project - Electricity Customer Behaviour Trial, 2009-2010 [dataset]'. Irish Social Science Data Archive. SN: 0012-00. Available at: www.ucd.ie/issda/CER-electricity.

Cook, J. et al. (2016) 'Consensus on consensus: a synthesis of consensus estimates on humancaused global warming', Environmental Research Letters, 11(4). doi: 10.1088/17489326/11/4/048002.

Department for Business Energy and Industrial Strategy (2019) Digest of UK Energy Statistics (DUKES) 2019. Department for Business, Energy and Industrial Strategy London, UK. Available at: https://www.gov.uk/government/statistics/digest-of-uk-energy-statisticsdukes-2019.

Department of Energy and Climate Change (2009) The UK Low Carbon Transition Plan: National strategy for climate and energy. HM Government. Available at: https://www.gov.uk/government/publications/the-uk-low-carbon-transition-plan-nationalstrategy-for-climate-and-energy.

Gallopin, G. et al. (1997) Branch Points: Global scenarios and human choice. Stockholm: PoleStar Series Report no. 7. Stockholm Environment Institute. Available at: https://greattransition.org/archives/other/Branch Points.pdf.

HM UK Parliament (2019) Climate Change Act 2008 (2050 Target Amendment) Order 2019, HM Government. Available at: https://www.legislation.gov.uk/ukpga/2008/27/part/1/crossheading/the-target-for-2050. 
Hunt, D. et al. (2012) 'Scenario archetypes: Converging rather than diverging themes', Sustainability, 4(4), pp. 740-772. doi: 10.3390/su4040740.

IEA (2013) Transition to sustainable buildings: Strategies and opportunities to 2050, OECD Publishing. Paris: OECD Publishing. doi: 10.1787/9789264202955-en.

Lombardi, R. et al. (2012) Designing Resilient Cities: a guide to good practice. Bracknell: IHS BRE Press. Available at: https://eprints.lancs.ac.uk/id/eprint/54963/.

McLoughlin, F., Duffy, A. and Conlon, M. (2012) 'Characterising domestic electricity consumption patterns by dwelling and occupant socio-economic variables: An Irish case study', Energy and Buildings. Elsevier B.V., 48, pp. 240-248. doi:

10.1016/j.enbuild.2012.01.037.

Office of Gas and Electricity Markets (2015) Insights paper on households with electric and other non-gas heating. London. Available at: https://www.ofgem.gov.uk/ofgem-

publications/98027/insightspaperonhouseholdswithelectricandothernon-gasheating-pdf.

Palmer, J. and Cooper, I. (2013) United Kingdom housing energy fact file, Department of Energy \& Climate Change. London. Available at:

https://www.gov.uk/government/uploads/system/uploads/attachment_data/file/345141/uk_ho using_fact_file_2013.pdf.

Raskin, P., Electris, C. and Rosen, R. (2010) 'The century ahead: Searching for sustainability', Sustainability, 2(8), pp. 2626-2651. doi: 10.3390/su2082626.

Rogers, C. et al. (2012) 'The urban futures methodology applied to urban regeneration', Proceedings of the Institution of Civil Engineers - Engineering Sustainability, 165(1), pp. 520. doi: 10.1680/ensu.2012.165.1.5.

Schwartz, P. (2012) The Art of the Long View: planning for the future in an uncertain world. New York: Crown Business. 